\title{
The Moderating Effect Of Culture On Full Versus Partial Mode Of Communication On Managerial Decision-Making
}

Faiza Khoja, University of Houston, Downtown

Chynette Nealy, (E-mail: CNealy@uhd.edu), University of Houston, Downtown

\begin{abstract}
This paper examines the effect of face-to-face versus electronic mode of communication on effective decision-making when moderated by the individualism and collectivism. Hypotheses that collectivists use face-to-face mode of communication and individualists use electronic mail mode of communication to make effective decisions were tested on managers from two countries (Mexico and United States).
\end{abstract}

\section{INTRODUCTION}

$T$

he 21st century has been declared an era of globalization of world economy characterized by outsourcing, foreign direct investments, international acquisitions, and alliances at a rise (Pan \& Zhang, 2004). However, cross-national businesses face increasing pressures and challenges not so much from factors such as price competition, language barriers, foreign currency, time differences etc. as from cultural differences. Hofstede (1993) believes that the spread of businesses onto the global stage brings the issue of national and regional differences to the fore. 'There is something in all countries called 'management', but its meaning differs to a larger or smaller extent from one country to another' (Hofstede, 1993). Thus, it is absolutely essential to learn and understand the different modes of communication adopted by culturally diverse nations to be able to effectively incorporate them in the decision making process. Culture can be defined as 'the collective mindset that distinguishes members of one nation from another' (Hofstede, 1991). Since each culture has unique values to guide human behavior, 'individualism and collectivism', which is the most widely studied cultural construct (e.g. Cox, Lobel, \& McLeod, 1991; Earley, 1993; Hofstede, 1980; 1991; 1993; 1998; Huff \& Kelly, 2005; Hoppe, 2004; Gabrenya, Latane \& Wang, 1995) is the primary focus of importance in our study as well.

The research question posited is: 'What modes of communication work most effectively in individualistic and collectivistic cultures?' This paper uses the media choices theories of media richness and social influence theory to suggest that collectivists use face to face mode of communication more than electronic mode of communication to make effective decisions and individualists use electronic mode of communication more than face to face mode of communication to make effective decisions. Information processing theory is used to argue that more effective decisions are made when collectivists use of face-to-face mode of communication than when individualists use electronic mail mode of communication. The unit of analysis is individuals within organizations and we evaluate the effect of media use instead of media choice (Dennis \& Kinney, 1998).

This paper examines prior studies and reviews that contribute to the overall discussion. So, although studies in this paper span with respect to time periods, future direction for research derives from prior studies. Moreover, sources referenced are valued for their quality in related literature. The first section presents a brief review of relevant literature. Hypotheses based on theoretical foundations are then articulated. The next section presents the methodology, followed by the research findings. The final section presents a discussion of results, limitations of the study and future direction. 


\section{RELEVANT LITERATURE}

We discuss previous research studies on the cultural construct of individualism-collectivism and modes of communication and their impact on decisions making, as the latter is the dependent variable in our study.

\section{Individualism- Collectivism}

Individualism-Collectivism is one of the most important dimensions of cultural to- date that has consistently been featured in the findings of cross-cultural studies (Triandis, 1995). Four distinct attributes can help define individualism and collectivism. An individualistic culture (U.S. U.K. etc.) is one where individual autonomy is stressed, personal goals over-ride group goals, individual preferences, attitudes and interests govern individual behaviors, and individuals treat relationship temporally (Triandis, 1995). A collectivistic culture (e.g. China, Mexico, India), on the other hand, is one where the focus is on group association, and group goals over-ride personal goals. Social norms, duties, and obligations govern social behaviors of collectivists who inturn value relationship and harmony and do not associate any cost with it (Tan, Wei, Watson, Clapper, \& Mclean, 1998a; Triandis 1995). Thus, in an individualistic culture, needs, values, and goals of the individual take priority over the needs, values and goals of the group. In a collectivistic culture, the needs, values, and goals of the group take priority over the individuals (Gudykunst, Gao, Schmidt, Nishida, Bond, Leung, Wang, \& Barraclough, 1992). To define the dimension of individualism-collectivism, previous researchers have used labels such as cooperation versus individualism and collaterality versus individualism (Hofstede, 1984).

\section{Modes of Communication}

Communication is defined as 'the exchange of information and transmission of meaning' (Katz \& Kahn, 1978). People communicate for three purposes: to inform, to persuade, and to entertain (DuFrene \& Lehman, 2004). While these objectives seem simple, the communication process is only effective when people understand each other, stimulate others to take action and encourage others to think in new ways (Thill \& Bovee, 2002). Selecting a suitable channel for transmitting the message increase effective communication outcomes. For example, according to media richness theory (Daft \& Lengel, 1986) verbal and full mode of communication often described as face to face communication enhances clarity, efficiencies (Daft, Lengel, \& Trevino, 1987; Straus \& McGrath, 1994) and lessens the chances of misunderstanding due to the ability of the medium to transmit multiple cues (e.g. tone of voice, gestures), immediacy of feedback, language variety, and the personal focus of the medium (Dennis \& Kinney, 1998). In contrast, electronic modes of communication, which is identified as the least richest form of nonverbal and partial communication (Daft \& Lengel, 1986) provides access to 24 hours global communication in the marketplace and fosters candidness in group discussions (Tan et. al., 1998a; Tan, Wei, Watson, Walczuch, 1998b).

\section{Individualism-Collectivism and Modes of Communication}

The growing global marketplace comprised of diverse cultural and ethnic backgrounds with continuing advances in technology mandates effective communication. These challenges increase the need for proficiency in verbal and full communication skills that is displayed when using video teleconferences. Similarly, effective nonverbal and partial communication shown daily via the use of electronic mail messages is needed. Thus, it is important to understand culturally preferred and used mode of communication for organizations to effectively develop and implement decisions.

In a more recent study, Tan et. al. (1998a) examined whether and how computer mediated communication $(\mathrm{CMC})$ reduces majority influence and thereby, enhances the quality of decisions in some situations. Three settings (only face to face, face to face and $\mathrm{CMC}$, and only $\mathrm{CMC}$ ) were compared to measure the impact of CMC on majority influence. They predicted the relationship to be moderated by national culture and task type. The results show that the impact of CMC was contingent upon national culture. In an individualistic culture, majority influence is strongest in face to face setting, followed by face to face and CMC setting and finally in only CMC setting. This is because individualists are encouraged to be candid and speak their mind and minority individualists are likely to exploit CMC 
more so then they can use face-to-face communication to their advantage. On the other hand, to maintain harmony by avoiding confrontation, minority collectivists do not challenge the majority in any of the settings mentioned above.

\section{THEORY AND HYPOTHESES}

Communication theory has evolved over several decades. The new communication theory incorporates social context in viewing media use within organizations (Fulk \& Boyd, 1991). Thus, media choice theories are categorized based upon whether they emphasize rational or social explanations (Trevino, Webster \& Stein, 2000; Webster \& Trevino, 1995). The media richness theory originally proposed by Daft and Engel (1986) assumes that communication behavior is objective, regulated and rational. This theory argues that managers could improve performance by matching media characteristics to organizational tasks. It also postulates that media varies in media richness based on their ability and capacity to facilitate shared meanings (Dennis \& Kinney, 1998).

The social influence theory proposed by Fulk and colleagues (Fulk \& Boyd, 1991; Fulk, Schmitz \& Steinfeld, 1990; Fulk, Steinfeld, Schmitz, \& Power, 1987) assumes that communication behavior is subjective and is influenced by co-workers' personal experiences and their social environment. It ranges from the influence of a communication partner's attitudes or preferences on an individual's media choice in a particular situation, to the influence of coworker's and supervisor's attitudes on one's more general attitudes towards media and broader patterns of use. It is determined that social influence theory can impact both traditional and new media use. The two theories; media richness theory and social influence theory are not necessary mutually exclusive and complementarity of these two conceptual views have extended the current literature on media choices, attitudes, and use to a certain extent (Trevino et. al., 2000; Webster \& Trevino, 1995). We use the complementarity approach in our study.

In this research paper, we suggest that individuals use media based on the saliency of the objective features that are inherently determined by the social norms. We posit that the ability to carry nonverbal cues is more salient to collectivist, as they prefer face-to-face mode of communication based on their norms of group affiliation, group harmony, and face saving (Argyle, Henderson, Bond, lizuka, \& Contarello, 1986). Collectivists in a group are likely to understand each other and communicate their ideas clearly and successfully through both verbal and non-verbal cues and can attain conclusive and prudent decisions that are for the benefit of the group. For them group goals and social relationship concerns prevail over task concerns (Triandis, 1995; Chen, Chen \& Meindl, 1998). Collectivists are less likely to make effective decisions using electronic mode of communication, as that does not allow them to make use of the non-verbal cues that are critical for their decision-making. Thus:

Hypothesis 1a: Collectivists are likely to use face to face mode of communication more than electronic mode of communication for effective decision-making.

In contrast, candidness is a salient feature for individualists who want to express their opinion and be heard, and electronic mode of communication provides them the medium to do that willingly (Tan et. al., 1998a). Thus, individualists can freely and openly express their ideas in a group without having to meet each other, as they are selfopinionated and for them tasks and self-interest take priority over group goals and social relationships (Triandis, 1995, Chen et. al., 1998). Hence, they do not find the need to use non-verbal cues to maintain group identity. Therefore:

Hypothesis 1b: Individualists are likely to use electronic mode of communication more than face to face mode of communication for effective decision-making.

The information processing theory views organizations essentially as information processors predisposed to reducing uncertainty and equivocality, by processing information (Daft \& Lengel, 1986; Keller, 1994; Subramanium, Rosenthal, \& Hatten1998). The most basic assumption of this theory is that organizations are open social systems that must process information to accomplish tasks. Information processing involves sharing, coordination, open communication and diverse problem-solving skills among individuals in a group (Daft et. al, 1987). Drawing from the information processing theory it is posited that collectivists, who are likely to use a richer mode of communication than individualists, have access to more information that they can use to make effective decisions. This is primarily because in face-to-face mode of communication information is formally and informally conveyed through both verbal 
and non-verbal mechanisms. In an electronic mode of communication, information is only what is stated. Tone of voice, body language, symbols and reactions cannot be accounted for. Therefore, both the quality and quantity of information exchanged and shared among collectivist group members is more than the information shared by individualists in a group, which collectivists can use to their advantage. Hence:

Hypothesis 2: Collectivists using face-to-face mode of communication are likely to make more effective decisions than individualists using electronic mode of communication.

\section{SAMPLE}

This study is based on the responses of three hundred managers, one hundred and fifty each from Mexico and the United States (USA). According to Hofstede's (1984) scale, Mexico is (30) on a country individualism index, which means that it is low on individualism and high on collectivism. On the same index, USA is (91), which means that it is high on individualism and low on collectivism.

\section{TASK}

A simulation was designed dealing with implementing different operational strategies that included introducing new products and services to enhance customer base. Data was developed using the North American Trade Agreement (NAFTA), a 1994 agreement reached between the United States, Mexico and Canada that eliminated a variety of hindrances to establish free trade between the three countries. Instructions and group assignments were given to participants on the job-related simulation. The overall objective focused a two-month period with a proposal due at the end describing project activities and experiences. The two-month period was used to control speed, which influences group task performance (Straus \& McGrath, 1994).

Groups were instructed to use any or both of the two different modes of communication, face to face and electronic mail. Work groups in both the countries have electronic mail access and are adept at using it. This controls for any difference in choosing communication medium due to technological variations. Individuals in a group asked to maintain a record of meetings held. The records should include, the mode of communication used, the number of times they met, the input by each member to the project at hand and a brief meeting summary. It was explained that performance evaluations would be on an individual basis to control for the effect of group identify at the end of two months.

\section{MEASURES}

Individualism and collectivism Wagner and Moch's (1986) scale was used to confirm the variance between the two countries on the cultural dimension of individualism and collectivism. This scale consists of three subconstructs on the dimension, beliefs, values and norms. All of these sub-constructs are found to be relatively independent of one another, hence, confirming discriminant validity. Related literature supports this assertion, in that they used the same measure for testing cultural differences in groups (Chen, Meindl \& Hunt, 1997).

The participants completed a questionnaire, confirming cultural variations, in the introductory meeting. Cornbach's alpha was calculated to ascertain the reliability of this instrument on the sample. An acceptable reliability of 0.8 for exploratory research (Nunnally \& Bernstein, 1994) resulted.

\section{Mode of Communication}

Participants were asked to complete the questionnaire shown in Table 1. The communication questionnaire is a modified version of the one used by Smith, Smith, Olian, Sims, O'Bannon, \& Scully,1994). The questionnaire measured the mode of communication that is preferred by individualists and collectivists. Communication frequency, number of times the groups met face to face or via electronic mail, and communication effectiveness were all used to measure the extent to which groups discussed projects. Records maintained by the members of each group were used to cross-tabulate communication measures for accuracy. 
Table 1: Communication Questionnaire

\begin{tabular}{|ll|}
\hline 1. & How many times did you meet face to face? \\
\hline 2. & Approximately how long were the meetings (average)? \\
\hline 3. & How many times did you communicate through electronic mail? \\
\hline 4. & Approximately for how long would electronic (online) communication (average)? \\
\hline 5. In face to face meeting, did you exchange ideas \\
\hline & a. related to the project? \\
\hline b. unrelated to the project? \\
\hline 6. In the electronic mail (online) meetings, did you exchange ideas \\
\hline a. related to the project? \\
\hline b. unrelated to the project? \\
\hline 7. Which mode of communication do you prefer and why? \\
\hline
\end{tabular}

\section{Effective Decision-Making}

A Likert scale ranging from (1) very poor to (5) very superior with middle points labeled poor, average and good was used to assess three criterion: (a) justification for the group accepting or rejecting a new strategy and or maintaining the old ones, (b) generation of multiple alternatives and (c) quality of recommendation.

\section{Control Variables}

Demographic and other factors were included as control variables, as they have seen to influence the process of communication in previous research (Smith et. al., 1994; Williams \& O'Reilly, 1998). These control variables were: age, gender, education, years of work experience and tenure with the company. Data for the control measures was obtained during initial review of company records. Language was also included as a control variable (Mexico (1) and USA (2)). This was to reduce any instruction differences between the two countries. Group size and identifiability (Wagner, 1995) was controlled by maintaining a group size of four and indicating to the groups prior to the study, that each member of the group would be evaluated individually and not just as a group.

\section{RESULTS}

Responses to the questions designed to assess the hypotheses were t-tested to determine the differences in means using a (.05) level of significance. Data (3.60 and 4.01, $\mathrm{t}=-4.25, \mathrm{p}=.000)$ supported Hypothesis la: Collectivists are likely to use face to face mode of communication more than electronic mode of communication for effective decision- making. Thus, it is more likely that the collectivist group (Mexican managers) exchanged information and performed well within groups, making well-informed decisions, using more face-to-face mode of communication than electronic mail. They used the former mode of communication extensively, as that is also their preferred mode.

In contrast, the individualist group (United States managers) used electronic mode as their primary mode of communication to exchange information and attain effective decisions. The findings ( 3.60 vs. $4.01, t=-4.25, \mathrm{p}=$ $.000)$ supported Hypothesis $1 b$ : Individualists are likely to use electronic mode of communication more than face to face mode of communication for effective decision-making. It is worthy of noting, the findings may be a result of using a competitive management style.

As predicted, Hypothesis 2: Collectivists using face to face mode of communication are likely to make more effective decisions than individualists using electronic mode of communication $(4.01$ vs. $3.80, t=2.45, p=.015)$ is also supported. The collectivist group using face-to face mode of communication is likely to infiltrate more information from both verbal and non-verbal expressions than the individualist groups, who are deprived of the excess information due to personal contact. 


\section{DISCUSSION}

Previous researchers have either evaluated the relationship between national culture and decision-making (Gibson \& Saxton, 2005; Pan \& Zhang, 2004; Sosik \& Jung, 2002) or have studied mode of communication and decision-making (Hedlund, Ilgen, \& Hollenbeck, 1998; Murthy \& Kerr, 2004). To the best of our knowledge, no other study has looked at a combined relationship of national culture, mode of communication and decision-making. Research conducted by Tan et. al. (1998a; 1998b) differ from ours, in their assessment of the dependent variable. Our study is also unique in that it uses theoretical justifications in explaining the relationships.

Learning about preferred mode of communication will help companies and managers to effectively function in a new environment given the North American Foreign Trade Agreement. For instance, if an American company invests in a joint venture with a firm in Mexico (collectivist culture), the American managers (individualist culture) should be aware that Mexicans prefer more face to face communication than the electronic mode. Therefore, if any important issue is to be discussed, a face-to-face interaction is appreciated and respected and is known to positively influence decision-making.

The globalization of our marketplace has brought attention to the need for understanding characteristics and effects of culture on managerial applications. We agree that organizations and management theories are culturally bound, and there is no such thing as a universal theory of management (Hofstede, 1993). It's important to enter the global market knowledgeable about culture, language, and work ethics to name a few.

Limitation

One of the major limitations of this research paper is self-reporting. There is no mechanism of reporting data objectively, for both independent and dependent variables. Also, it is not feasible to hypothesize all the existing cultural differences prevailing in communication literature. Therefore, only one major cultural difference was focused on.

\section{CONCLUSION}

This paper extends the current literature on communication by testing the relationship between mode of communication used by individualist and collectivist managers to make effective decisions within their groups. Practically, it draws from management structures to current organizational challenges faced by working in culturally diverse environments. Determining which mode of communication is required and accepted will provide companies a competitive foothold in the new culture and will ease the path for more important strategic decisions and implementations.

\section{REFERENCES}

1. Argyle, M., Henderson, M., Bond, M., Iizuka, Y., \& Contarello, A. (1986).Cross-cultural variations in relationship rules. International Journal of Psychology, 21, 287-315.

2. Chen, C. C., Chen, X. P., \& Meindl, J. R. 1998. How can co-operation be fostered? The cultural effects of individualism and collectivism. Academy of Management Review, 23(2): 285-304.

3. Chen, C. C., Meindl, J. R., \& Hunt, R. G. 1997. Testing the effects of vertical and horizontal collectivism: A study of reward allocation preferences in China. Journal of Cross-Cultural Psychology, 28(1): 44-70.

4. Cox, T., Lobel, S., \& McLeod, P. 1991. Effects of ethnics group cultural differences in cooperative and competitive behavior on a group task. Academy of Management Journal, 34(4): 827-847.

5. Daft, R. \& Lengel, R.,1986. A proposed integration among organizational information requirements, media richness, and structural design. Management Science, 32: 554-571.

6. Daft, R., Lengel, R., \& Trevino, L., 1987. Message equivocality, media selection, and manager performance: Implications for information systems. MIS Quarterly, September: 355-366.

7. Dennis, A. \& Kinney, S., 1998. Testing media richness theory in the new media: The effects of cues, feedback, and task equivocality. Information Systems Research, 9(3): 256-275. 
8. $\quad$ Earley, P. 1993. East meets West meets Mideast: Further explorations of collectivistic and individualistic work groups. Academy of Management Journal, 36 (2): 319-348.

9. Fulk, J. \& Boyd, B.,1991. Emerging theories of communication in organizations. Journal of Management, 17: 407-446.

10. Fulk, J., Schmitz, J., \& Steinfeld, C., 1990. A social influence model of technology use. In J. Fulk \& C. Steinfield (Eds.), Organization and Communication Technology: 117-141. Newbury, CA: Sage.

11. Fulk, J., Steinfield, C., Schmitz, J., \& Power, J. 1987. A social information processing model of media use in organizations. Communication Research, 14, 529-552.

12. Gabrenya, W., Latane, B., \& Wang, Y. 1983. Social loafing in cross-cultural perspective. Journal of CrossCultural Psychology, 14: 368-384.

13. Gibson, C., Saxton, T., 2005. Thinking Outside The Black Box: Outcomes of team decisions with third party intervention. Small Group Research, 36(2): 208-237.

14. Gudykunst, W., Gao, G., Schmidt, K., Nishida, T., Bond, M., Leung, K., Wang, G. \& Barraclough, R. 1992. The influence of individualism-collectivisim on communication in ingroup and outgroup relationships. Journal of Cross-Cultural Psychology, 23, 196-213

15. Hedlund, J., Ilgen, D., \& Hollenbeck, J., 1998. Decision accuracy in computer-mediated versus face-t-face decision-making teams. Organization Behavior and Human Decision Processes, 76(1): 30-48.

16. Hofstede, G., (1980, 1984). Culture's consequences: International differences in work-related values. Beverly Hills, CA: Sage.

17. Hofstede, G., 1991. Culture and Organizations: Software of the Mind. McGraw-Hill: London.

18. Hofstede, G., 1993. Cultural constraints in management theories. Academy of Management Executive, 7(1): 81-94.

19. Huff, L., Kelly, L., 2005. Is collectivism a liability? The impact of culture on organizational trust and customer orientation: A seven nation study. Journal of Business Research, 58(1): 96-102.

20. Katz, D. \& Kahn, R. (1978). The social psychology of organizations (2nd Ed.). New York: John Wiley \& Sons.

21. Keller, R. 1994. Technology-information processing fit and the performance of R\&D project groups. A test of contingency theory. Academy of Management Journal, 37(1): 167-179.

22. DuFrene, D., Lehman, C., 2004. Concept, content, construction, and contingencies: Getting the horse before the powerpoint cart. Business Communication Quarterly, 67(1): 84-88.

23. Murthy, V. \& Kerr, D., 2004. Comparing audit team effectiveness via alternative modes of computermediated communication. Auditing, 23(1): 141-153.

24. Nunnally, J. \& Bernstein, I. (1994) Psychometric Theory New York: McGraw Hill, 3rd ed.(required)

25. Pan, F. \& Zhang, Z., 2004. Cross-cultural challenges when doing business in China. Singapore Management review, 26(1): 81-91.

26. Smith, K., Smith, K., Olian, H., Sims, H., O’Bannon, D., \& Scully, J. 1994. Top management team demography and process: The role of social integration and communication. Administrative Science Quarterly, 39: 412-438.

27. Sosik, J. \& Jung, D., 2002. Work group characteristics and performance in collectivistic and individualistic cultures. Journal of Social Psychology, 142(1): 5-24.

28. Straus, S. \& McGrath, J. 1994. Does the medium matter? The interaction of task type and technology on group performance and member actions. Journal of Applied Psychology 79(1), 87-97.

29. Subramanium, M., Rosenthal, S., \& Hatten, K., 1998. Global new product development processes: Preliminary findings and research propositions. Journal of Management Studies, 35(6): 773-797.

30. Tan, B., Wei, K., Watson, R., Clapper, D., \& Mclean, E. 1998a. Computer-mediated communication and majority influence: Assessing the impact in an individualistic and collectivistic culture. Management Science, 44(9): 1263-1279.

31. Tan, B., Wei, K., Watson, R., \& Walczuch, R. 1998b. Reducing status effects with computer-mediated communication: Evidence from two distinct national cultures. Journal of Management Information Systems, 15(1): 119-132.

32. Thill, J. \& Bovee, C. Excellence in Business Communication, 5th edition. Prentice Hall, 2002.

33. Trevino, L., Webster, J., \& Stein, E. 2000. Making connections: Complementary influences on communication media choices, attitudes, and use. Organization Science, 11(2): 163-182. 
34. Triandis, H., 1995. Individualism and collectivism. Boulder, CO: Westview Press.

35. Wagner, J. \& Moch, M. 1986. Individualism-collectivism: Concept and measure. Group and Organization Studies, 11, 280-304.

36. Wagner, J. 1995. Studies of individualism-collectivism: Effects on cooperation in groups. Academy of Management Journal, 38, 152-172.

37. Webster, J. \& Trevino, L., 1995. Rational and social theories as complementary explanations of communication media choices: Two policy-capturing studies. Academy of Management Journal, 38(6): 1544-1573.

38. Williams, K. \& O'Reilly, C. 1998. Demography and diversity in organizations: A review of 40 years of research. Research in Organizational Behavior. 20: 77-140. 